\title{
ReVIEW | The Production and Consumption of Music in the Digital Age
}

Brian J. Hracs, Michael Seman and Tarek E. Virani Eds. New York and London: Routledge, 2016

ISBN: 9781138851658 (HB)

\author{
Sean Albiez \\ Southampton Solent University \\ sean.albiez@solent.ac.uk
}

Since the late 1980s, popular music scholars have directed critical attention to emerging digital technologies and the disruptive potential they afford for music making (see, for example, Durant 1990; Goodwin 1988). With the arrival of the World Wide Web in the middle of the 1990s, attention was also turned towards the transformation of distribution and consumption practices afforded by the Internet and the MP3 format (see Burnett 1995; Hayward 1995). A utopian strand of thinking running through earlier work was marked by a celebration of the democratizing potential of cheap and accessible music technologies. Such technologies enabled self-taught musicians to produce music through sequencing, sampling and mixing any number of sound sources, initially via hardware and then increasingly by utilizing computer software. In the process, the established centralized structure of the recording industry was undermined. Likewise, the arrival of the internet in the mid-1990s was viewed by some as having revolutionary potential for musicians and consumers to disintermediate sectors of the music industries, gaining autonomy and control over their creative, distribution and consumption practices.

In the current period, the disruptive potential afforded by emerging digital technologies is widely evident, and yet what was once astonishingly new has become quotidian. As this collection suggests, the celebratory and liberatory tone of those viewing the positive potential of the digital age twenty years ago now 
needs to be tempered by a more sober, post-digital assessment. The perspectives represented in this book collection are wide ranging and multi-perspectival, but are underpinned by approaches examining the economic geography of music in an era of constant, restless and large scale change. In doing so, the emphasis of the contributions is on the organisational transformation of different sectors of the music industries, the evolution of market dynamics and the activities emerging in consumer behaviours. How these have evolved and been restructured globally and locally, offline and online, and at a macro and micro level, is considered in a number of contexts: in cities; scenes; venues; festivals; retail outlets; and communities. Notably, though this publication clearly has an international dimension, all but one of the studies focuses on North America or Western Europe. However, in a collection of this size it is hard to see how it could have been more geographically inclusive. It does place an emphasis on how the people involved in each study (in Santiago, Toronto, New York, Paris, Amsterdam, London and Berlin) have negotiated the musical and technological terrain of their particular context, with several contributions using interviews and observational studies with participants. However, how the local has been transformed by translocality as a result of the connected world afforded by digital technologies is a theme constantly returned to throughout the book.

In place of the wide-eyed utopianism often promoted by publications such as Wired in early days of the WWW, the collection indicates how democratisation and disintermediation come at a price. Though many making, performing, distributing, promoting and consuming music may feel they have a level of flexibility and autonomy unachievable in earlier eras, Allan Watson argues that the price to be paid is the extensification and intensification of work. He describes how recording engineers and producers have precarious careers where they are required to be on constant call by clients, and where, as freelancers, periods of drought are followed by overly intense periods of intrusive work that blurs work and domestic space. Precariousness, intensification and extensification are themes encountered throughout the collection whether in the recording context, or for those working within record companies. Likewise, though digital technologies afford the possibility of musicians to take control of their careers, this collection also indicates how this control can also result in the need to become a digital polymath, adept at using any number of software packages to promote performances and distribute products. This enforced professionalization comes at the cost of the ability to focus on musical creativity alone, where musicians have to by necessity become entrepreneurs. As Hracs suggests, this can be potentially justified as a process of disintermediating the established music industry, to feel that there is greater authenticity in communicating musical works directly to potential audiences. However, doing it yourself can also mean that musicians financially exploit themselves with little hope of remuneration for work done.

Nevertheless, there are other areas of current musical activity that can be viewed more positively. For example, the increasing trans-localisation of music scenes through digital media in a connected world can actually benefit local music scenes. Virani outlines how a London venue has developed as a vibrant centre of local and trans-local activity through reciprocal work with other venues across the globe, reinvigorating rather than diluting the local scene. Likewise, as Wynn and Dominguez-Villegas indicate, festivals that have become increasingly 
economically important during the digital age afford economic and social exchanges that work in parallel with digital technologies, with place still mattering and being meaningful for musicians and fans alike, in contrast to the non-place of digital virtuality.

In terms of a broad overview of digital consumption practices, Leyshon et al. balance the positive and negative implications of consumers becoming increasingly involved in the promotion and production of music. In a democratizing sense, they argue we have entered a new technological democracy where the public can participate through crowd-funding and similar techniques, and input into the musical products they eventually consume. However, this process can be exploited by companies who wish to co-opt consumer expertise and activity, commodifying consumer desire and making greater profits with lower promotional costs.

On the whole, the collection provides a detailed and valuable overview of how the concerns of geographical study help us understand how the spaces and places of music in a digital era are produced and negotiated by participants. The book is a wide-ranging collection covering recording and production, work in the music industries, performance, artist perspectives, promotion, distribution and consumption, and it is difficult to identify comparable publications. There are existing studies that deal individually with each of these areas from a number of disciplinary positions. However, in specifically choosing to take the perspective of human and economic geography, the collection ensures that it acts as an important addition to the wider field. In pursuing this line of analysis, there is a sense that though digital technologies have resulted in many clear benefits in dismantling the exploitative professional music industries through a process of democratization and disintermediation, taking control has for many resulted in self-exploitation and little reward. More positively, digital technologies have enhanced real world connectivity and trans-local musical communication. The collection is therefore an important contribution to helping us understand the ambiguities and contradictions to be found in an increasingly technologically mediated experience of musicking.

\section{References}

Burnett, R. 1995. The Global Jukebox: The International Music Industry. London: Routledge.

Durant, A. 1990, A New Day for Music? Digital Technologies in Contemporary Music-making. In P. Hayward Ed. Culture, Technology and Creativity in the Late Twentieth Century. London: John Libbey: 175-196.

Goodwin, A. 1990. Sample and Hold: Pop Music in the Age of Digital Reproduction. In S. Frith and A. Goodwin Eds. On Record. London: Routledge: 258-273.

Hayward, P. 1995. Enterprise on the New Frontier: Music, Industry and the Internet. Convergence (1)1: 29-44. 